cells-suggested the possibility of more sinister haematological disorders, including plasma cell leukaemia and angioimmunoblastic lymphadenopathy. There was, however, no additional clinical or laboratory evidence for these diagnoses. The dramatic rise in the numbers of these cells was short lived with complete disappearance in three days. Although a renal biopsy was not performed, the renal failure was considered to be due to an acute hypersensitivity induced interstitial nephritis. Hydrocortisone, which was not given prophylactically to this patient, might have modified the immune and clinical response.

Management after thrombolytic treatment has been controversial and it is not clear whether coronary angioplasty is beneficial in preventing reocclusion of the reperfused artery. If threatened reocclusion occurs either within five days or after three months following initially successful thrombolysis our policy has been to reattempt reperfusion with streptokinase. In this patient reocclusion was prevented by readministration of streptokinase, but his severe symptoms of angina continued and coronary surgery was required. If thrombolytic treatment is to be repeated at a time when an allergic reaction is likely, non-antigenic agents such as recombinant tissue plasminogen activator should be used.

1 Gruppo Italiano Per Lo Studio Della Streptochinasi Nell' Infarcto Miocardico GISSI). Effectiveness of intravenous thrombolytic treatment in acute myocardial infarction. Lancet 1986;i:397-402.

2 ISIS Steering Committee. Intravenous streptokinase given within 0-4 hours of onset of myocardial infarction reduced mortality rate in ISIS 2. Lancet 1987; i:502.

3 White HD, Norris RM, Brown MA, et al. Effect of intravenous streptokinase on left ventricular function and early survival after acute myocardial infarction. $N$ Engl J Med 1987;317:850-5.

4 Sharma CVRK, Cella G, Parisi AF, Sasahara AA. Thrombolytic therapy N Engl f Med 1982;306:1268-76.

5 Straub PW, Boersma J, Rhyner N, et al. Plasmacytoma following thrombolytic treatment with streptokinase. Sch Med Wochenschr 1974;104:1891-2.

(Accepted 24 May 1988)

\section{Increased prevalence of bulimia nervosa among Asian schoolgirls}

\section{B Mumford, A M Whitehouse}

Transcultural Psychiatry Unit, Lynfield Mount Hospital, Bradford

D B Mumford, MRCPSYCH, senior registrar in psychiatry

University Department of Psychiatry, Addenbrooke' Hospital, Cambridge CB2 2QQ

A M Whitehouse, MRCPSYCH, clinical lecturer in psychiatry

Correspondence to: $\mathrm{Dr}$ Whitehouse.

Previous surveys of girls in school and higher education have yielded a prevalence of anorexia nervosa of 0.2 $0 \cdot 4 \%$ and of bulimia nervosa of $1 \cdot 3-1 \cdot 9 \%$. Few cases of anorexia nervosa or bulimia nervosa have been reported among non-white subjects. It might therefore be expected that the prevalence of eating disorders would be lower among Asian schoolgirls in Britain than among their white counterparts.

\section{Subjects, methods, and results}

We studied fourth and fifth year schoolgirls aged 14-16 at four schools in the Bradford metropolitan area selected for their high proportion of Asian pupils. The 26 item eating attitudes test and the body shape questionnaire were administered in the classroom by teachers. ${ }^{2}$ Subjects who scored above 20 on the eating attitudes test or above 140 on the body shape questionnaire were invited to attend for a semistructured interview at which the eating disorder examination was used. ${ }^{3}$ Details of their eating history were also collected. An eating disorder was diagnosed after discussion between us.

Overall attendance in the classes surveyed was $69 \%$ of the number enrolled; there was no reason to think that any of the girls were absent because of the survey. Girls of mixed or other ethnic origin or whose ethnic origin was in doubt were not included in the study population; 37 girls ( $6 \%$ of girls in school) refused to complete the questionnaire, and six questionnaires were inadequately completed and excluded. The remaining 204 Asian and 355 white girls constituted the survey population.

Scores obtained with the eating attitudes test had a skewed distribution and were logarithmically converted for statistical analysis. The mean score of the Asian girls was 10.6 (SD 9.0) and of the white girls 7.7 $(8 \cdot 0)$, the difference being significant $(t=4 \cdot 7$, $\mathrm{p}<0.001)$. The mean score obtained with the body shape questionnaire by the Asian girls was $73 \cdot 3(34 \cdot 2)$ and by the white girls $70.3(31 \cdot 6)$; this difference was not significant $(t=1 \cdot 1)$. Thirty $(15 \%)$ Asian and 42 $(12 \%)$ white girls had scores above the threshold for the questionnaires and were invited for interview; 22 Asian and 32 white girls were interviewed $(75 \%$ of the population invited). Bulimia nervosa was diagnosed according to criteria of the American Psychiatric Association ${ }^{4}$ in seven of the Asian and two of the white girls, giving a prevalence of $3.4 \%$ and $0.6 \%$ respectively, the difference being significant (Fisher's exact test, $\mathrm{p}<0.05)$. Anorexia nervosa was diagnosed ${ }^{4}$ in one Asian girl but was not found in any white girls.

\section{Comment}

The high prevalence of bulimia nervosa among the Asian girls in this survey was unexpected. Anorexia nervosa and bulimia nervosa are commonly thought to be the result of Western attitudes towards body shape, weight, and dieting behaviour. Data from the Indian subcontinent are scarce, but eating disorders are probably rare. This high prevalence of bulimia nervosa among Asian girls in the United Kingdom is probably a new phenomenon in these families. The Asian girls' higher scores with the eating attitudes test indicate that they were more concerned than the white girls about food intake and weight. Such concerns are likely to play a part in the aetiology of eating disorders.

A recent study in Birmingham showed an increased rate of self poisoning among young Asian women compared with British women. ${ }^{5}$ A previous study had found that the rates among Asians were lower than those among their white counterparts. This change suggests that Asians are increasingly adopting Western patterns of reacting to stress. Our finding of a higher prevalence of bulimia nervosa would seem to be a parallel phenomenon and highlights one difficulty facing Asian schoolgirls growing up in Britain.

We thank Mr W R Knight, director of educational services, Bradford, and the head teachers and staff at the schools for their cooperation in this study.

1 Garner DM, Olmsted MP, Bohr Y, Garfinkel PE. The eating attitudes test: psychometric features and clinical correlates. Psychol Med 1982;12:871-8. 2 Cooper PJ, Taylor MJ, Cooper Z, Fairburn CG. The development and validation of the body shape questionnaire. International fourmal of Eating Disorders 1987; 4:485-94.

3 Cooper Z, Fairburn CG. The eating disorder examination: a semistructured interview for the assessment of the specific psychopathology of eating disorders. International fournal of Eating Disorders 1987;6:1-8.

4 American Psychiatric Association. DSM III-R: diagnostic and statistical manual of mental disorders. Revised 3rd ed. Washington, DC: American Psychiatric Association, 1987

5 Merrill J, Owens J. Ethnic differences in self-poisoning: a comparison of Asian and white groups. Br f Psychiatry 1986;148:708-12.

(Accepted 2 fune 1988) 